\title{
Dynamic Signal Analyzer Developed With LabVIEW-RF Tools
}

\author{
Srinivasulu Sykam, Gale Allen \\ Department of Electrical and Computer Engineering and Technology \\ Minnesota State University, Mankato
}

\section{Introduction}

Signal distortion consists of changes in the original amplitude, frequency, or phase of a signal. Some of the functions of a Dynamic Signal Analyzer were implemented in a LabVIEW program which controls a NI Signal Analyzer.

\section{Laboratory Equipment}

Two sets of National Instruments LabVIEW-controlled RF systems are shown in Figure 1.

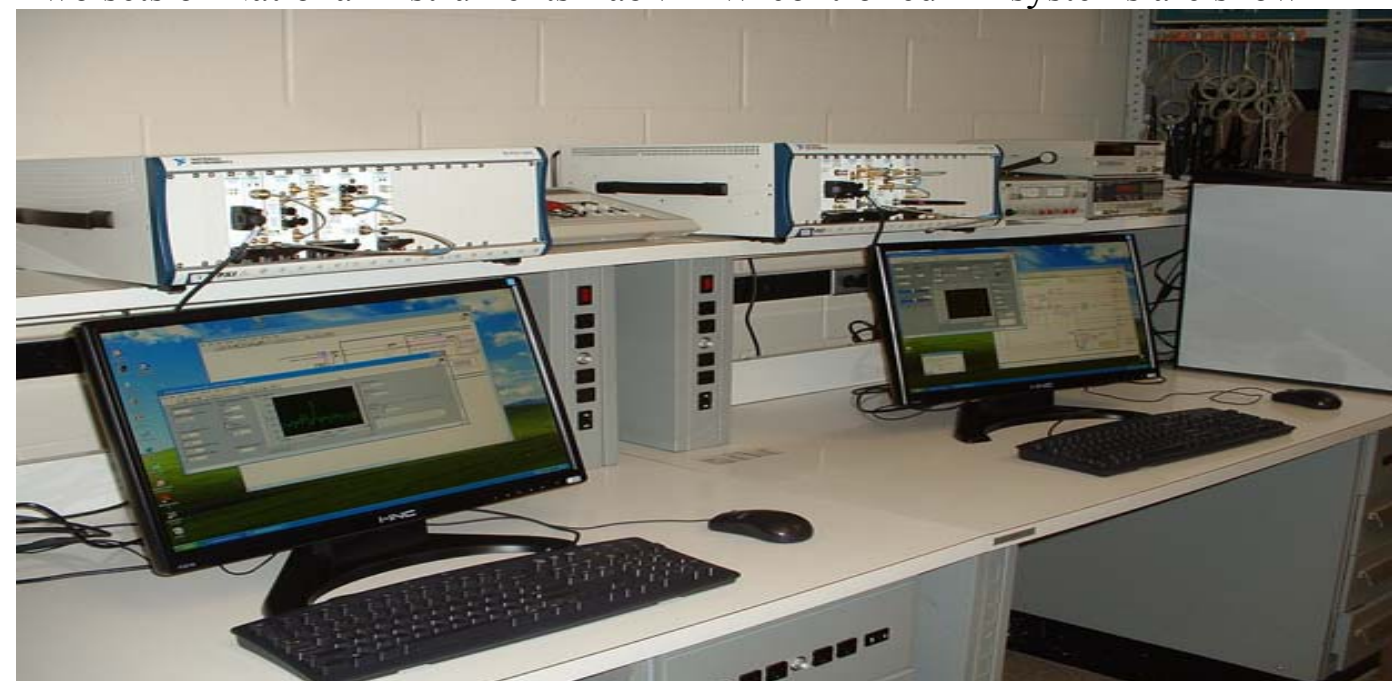

Figure.1. Two NI RF Systems

Each system has a signal generator (Figure 2) and a signal analyzer (Figure 3) and a second digitizer. These are housed in the NI PXI-1045 chassis.

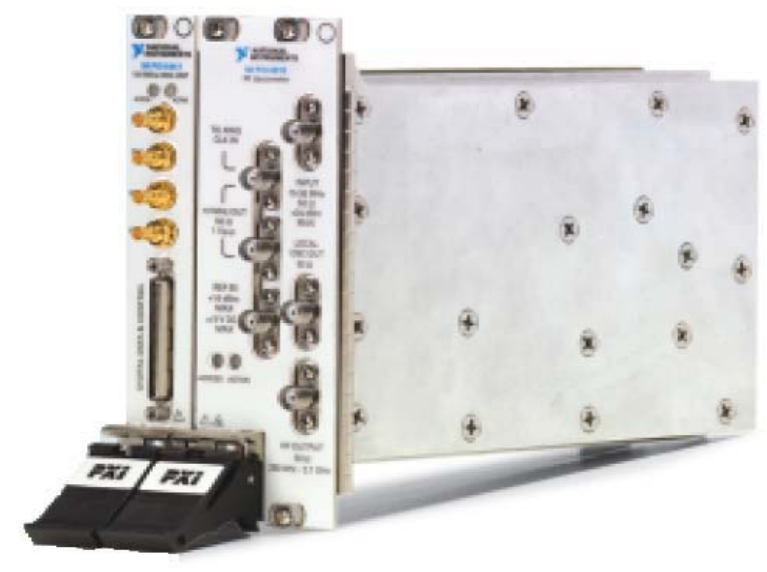

Figure 2. NI PXI-5671 2.7 GHz RF Vector Signal Generator with Digital Upconversion 


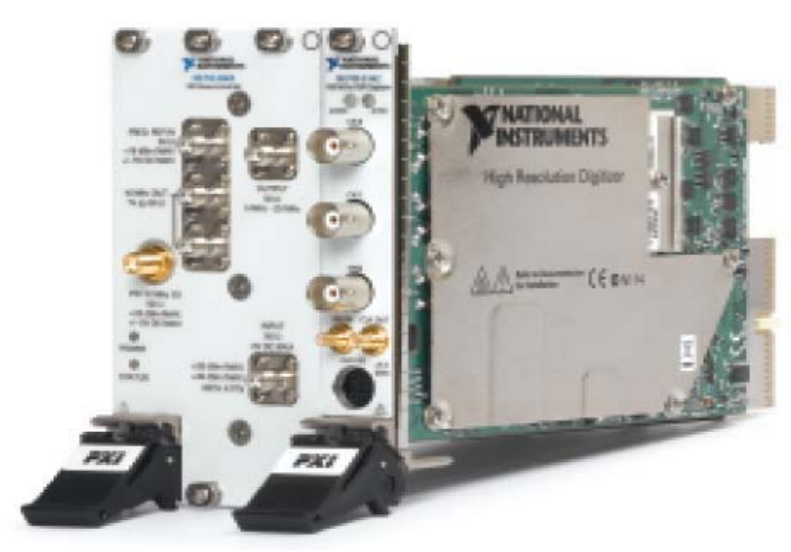

Figure 3. NI PXI-5661 2.7 GHz RF Vector Signal Analyzer with Digital Downconversion

\section{Dynamic Signal Analyzer}

The main function of Dynamic signal analyzer is to transform the data from time domain to frequency domain. Frequency domain conversion cannot be done on continuous signals since they are not sampled and digitized. The block diagram of the DSA is shown below in Figure 4.

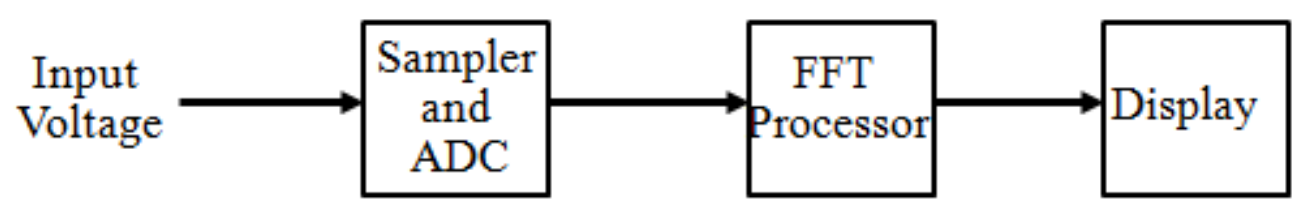

Figure.4. Block Diagram of Dynamic Signal Analyzer

In general the goal was to add features and capabilities to the existing NI Advanced Harmonic Signal Analyzer program as provided by National Instruments.

\section{Initial Work}

The initial work involved determining the features to be developed and included in the final design. The measurement capabilities of Distortion Analyzer, Agilent 35670A, were studied and considered for inclusion in the LabVIEW-based design. Some of the capabilities were provided by National Instruments in the Advanced Harmonic Signal Analyzer demonstration program. The features of the Agilent equipment and the demonstration program are included in Table 1 below along with a plan for including selected features.

\section{Added Features}

Within the time period available for this project only few of the features (mentioned as DEVELOPED in Table.1) could be added. In Table 1,

- DEVELOPED: the features which were added to the new design,

- YES: the feature is already present and

- FUTURE: the feature that can be added in the future.

\begin{tabular}{|l|l|l|}
\hline $\begin{array}{l}\text { Existing Measurements in } \\
\text { Agilent 35670A }\end{array}$ & $\begin{array}{l}\text { Existing Measurements in the } \\
\text { NI Advanced Harmonic }\end{array}$ & $\begin{array}{l}\text { Measurements } \\
\text { Developed/Improved }\end{array}$ \\
\hline
\end{tabular}




\begin{tabular}{|l|l|l|}
\hline & Analyzer Measurement.vi & \\
\hline Frequency domain & NO & FUTURE \\
\hline Frequency response & & \\
\hline Power spectrum & NO & FUTURE \\
\hline Frequency spectrum & & \\
\hline Coherence & & FUTURE \\
\hline Cross spectrum & NO & FUTURE \\
\hline Power spectral density & NO & DEVELOPED \\
\hline Time domain & & FUTURE \\
\hline Time waveform & & FUTURE \\
\hline Auto-correlation & NO & DEVELOPED \\
\hline Cross-correlation & NO & FEVELOPED \\
\hline Orbit diagram & NO & FUTURE \\
\hline Amplitude domain & NO & \\
\hline Cumction (CDF) & NO & \\
\hline Histogram & & FEF \\
\hline
\end{tabular}

Table.1. Project Plan and Prospects

Stage 1: In this stage, the NI Single Tone Generation vi was removed from within the NI demo vi. The output from this program was applied as input to the remaining Advanced Harmonic Signal Analyzer vi. 


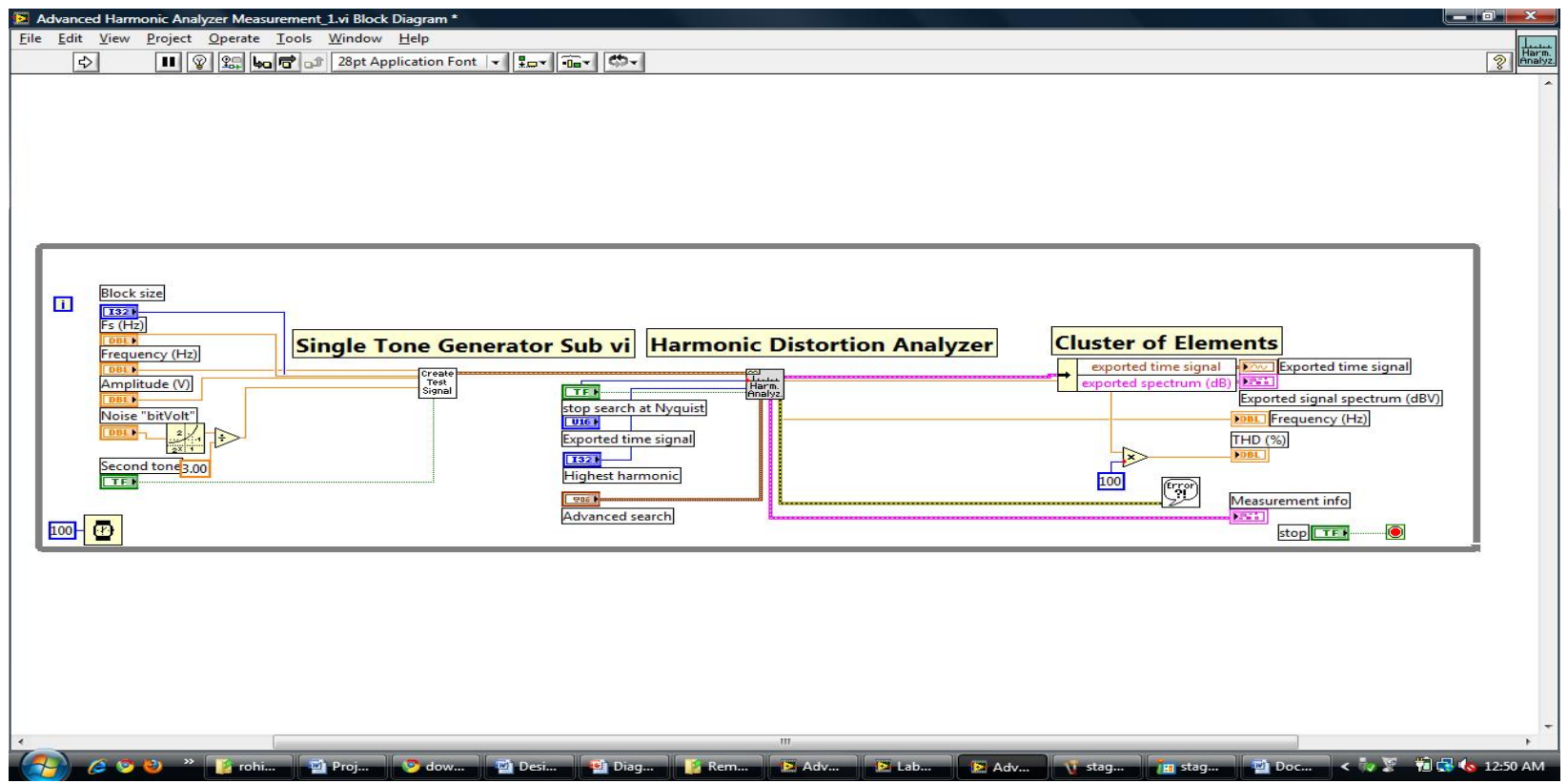

Figure.5. Advanced Harmonic Signal Analyzer

Stage 2: In this stage Signal Tone Generator blocks have been replaced with NI_RFSA blocks to collect input signal from external source and implementation of Dynamic Signal Analyzer. Single Tone Generator was able to generate a single tone but the input signal was generated internally. This program was not able to collect the signal generated by an external source. In this project, RFSA down converter (NI-PXI-5600) was used as the signal source. To collect this external signal generated on to the PC and further processing, the Single Tone block has been replaced with the RFSA blocks.

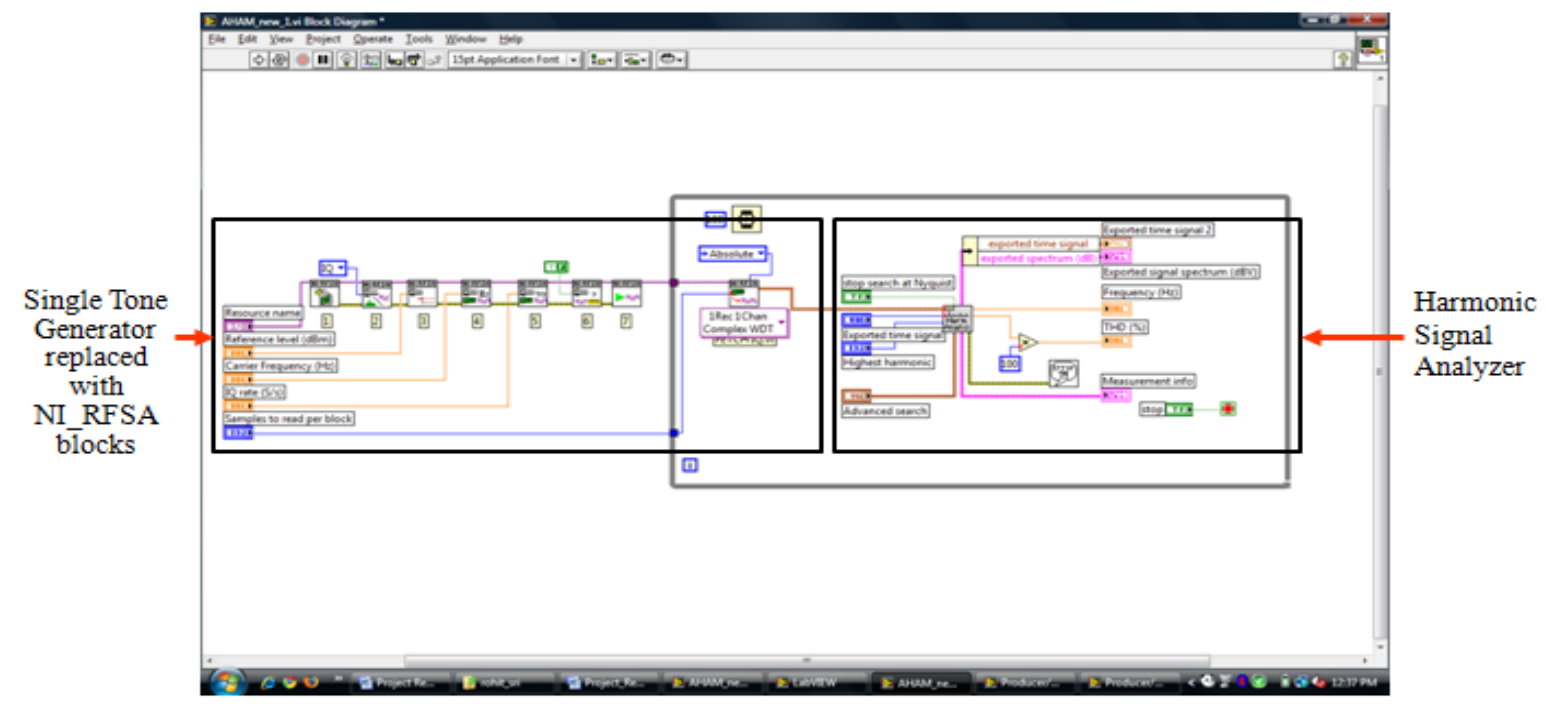

Figure.6. Advenced Harmonic Signal Analyzer with NI_RFSA blocks

Fundamental frequency is the lowest frequency in the harmonic series. Any device producing a fundamental frequency also produces harmonic frequencies that are multiples of fundamental 
frequency. All the harmonic frequencies are lower in level compared to the fundamental frequency. While measuring Total Harmonic Distortion of an amplifier, the extent of distortion is the measure of the level of harmonics at the input to the level of harmonics at the output.

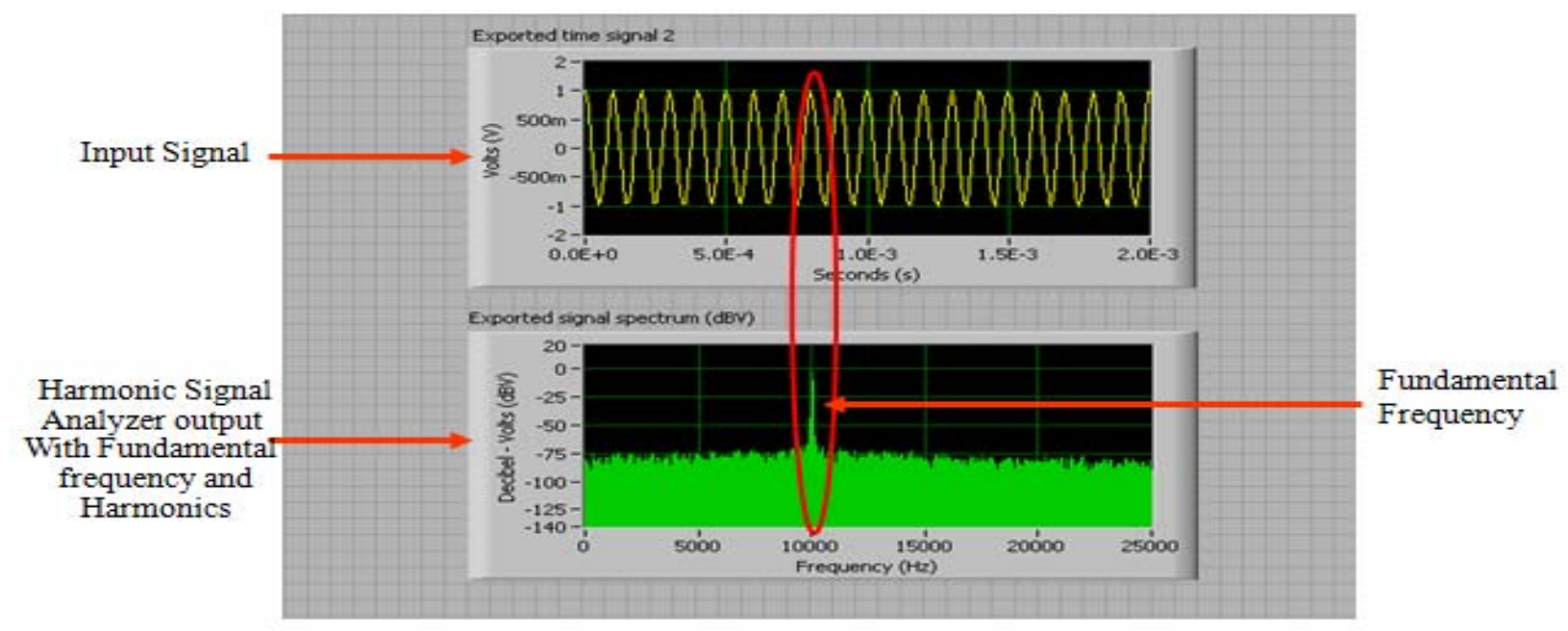

Figure.7. Output of the Harmonic Signal Analyzer with RFSA input

Stage 3: In this stage, different features were developed and added to the Dynamic Signal Analyzer vi. NI_RFSA blocks take the signal from any signal generator and processes through different stages of signal acquisition and signal processing. Output of NI_RFSA blocks is given to the Harmonic Distortion Analyzer which performs the harmonic analysis on the signal and Total Harmonic Distortion of the signal is determined.

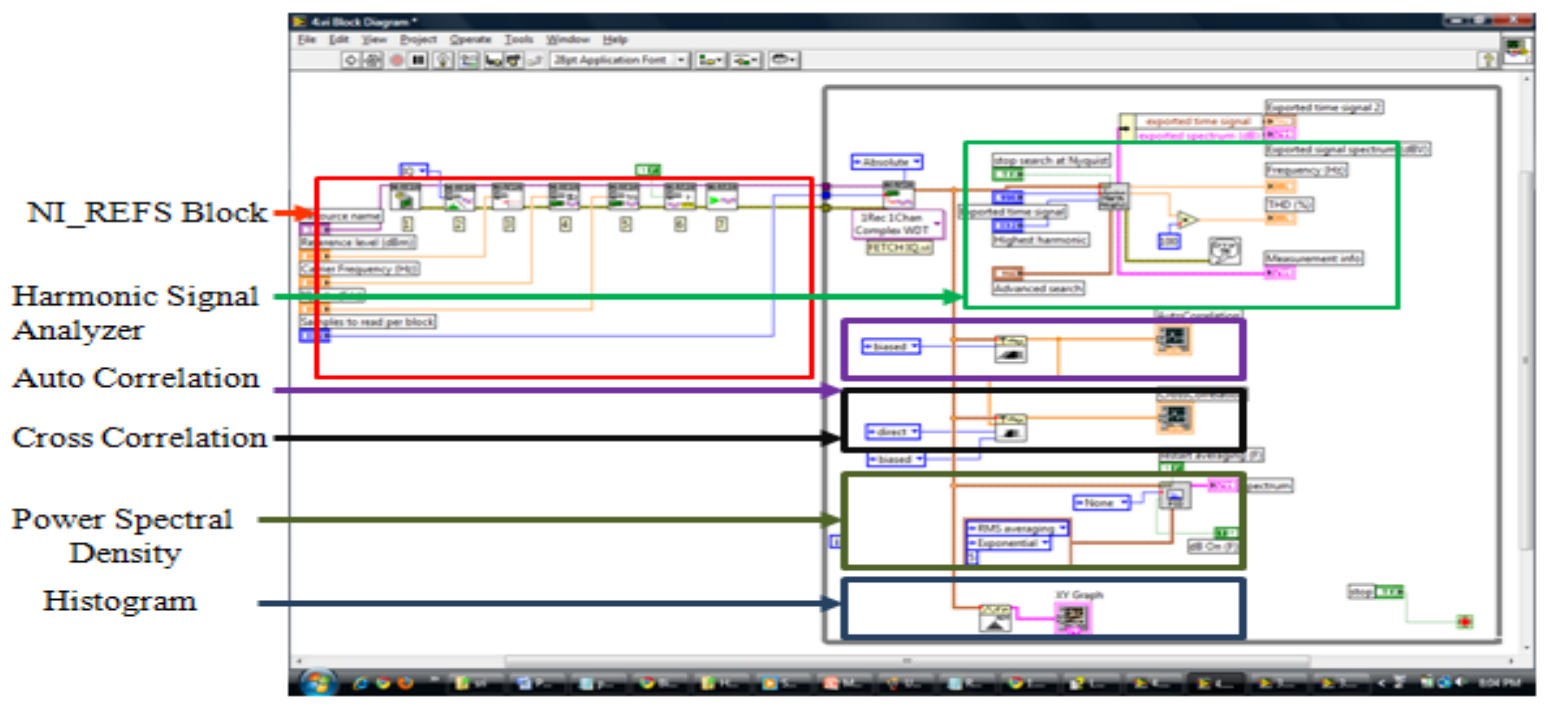

Figure.8. Final View of the Project

Below figure shows the expected outputs for the features added. 


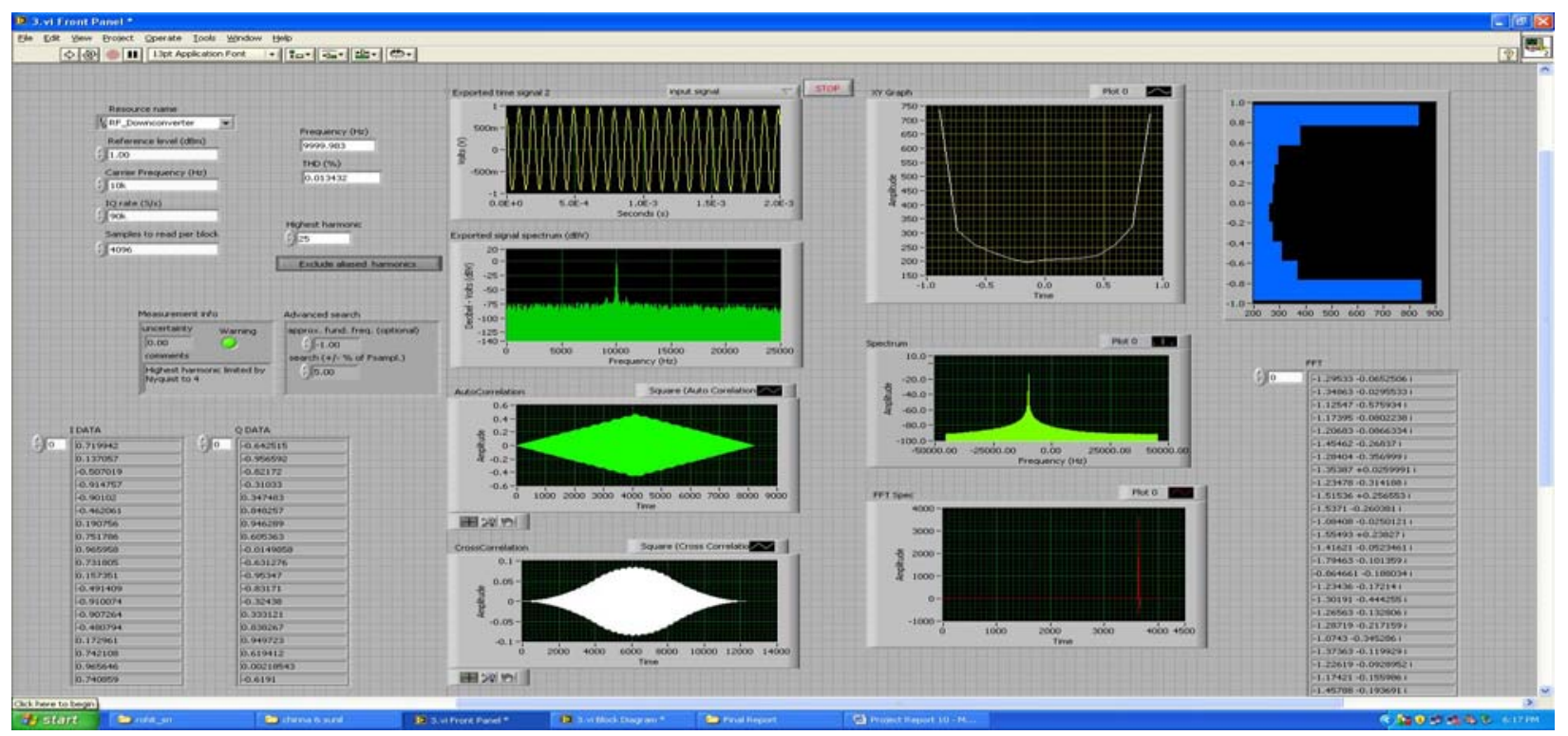

Figure.9. Final Output

\section{Conclusion}

To conclude on the whole, general purpose Dynamic Signal Analyzer vi which can take signal from an external signal device has been developed and has been successfully implemented using LabVIEW. The future developments that can be done on this design have been mentioned in Table.1.

The authors would like to thank Dr. William Hudson, ECET Department Chair, for his efforts to help improve the communications laboratory and for his ongoing encouragement and support of students and faculty. Also the staff of National Instruments provided valuable guidance on operation of the RF instruments and LabVIEW programming.

- Minnesota Center for Excellence in Engineering \& Manufacturing and National Instruments for supporting acquisition of the NI RF equipment.

\section{References}

[1]. http://en.wikipedia.org/wiki/Total_harmonic_distortion

[2]. http://www.dogstar.dantimax.dk/tubestuf/thdconv.htm

[3]. ww.geappliances.com/email/lighting/specifier/downloads/Total_Harmonic_Distortion.pdf

[4]. http://sine.ni.com/nips/cds/print/p/lang/en/nid/203069

[5]. http://sine.ni.com/nips/cds/view/p/lang/en/nid/13478

[6]. http://sine.ni.com/nips/cds/view/p/lang/en/nid/201568

[7]. http://sine.ni.com/nips/cds/print/p/lang/en/nid/11535

[8]. http://sine.ni.com/nips/cds/view/p/lang/en/nid/202655

[9]. http://www.ni.com/pdf/manuals/370840a.pdf

[10].http://www.itl.nist.gov/div898/handbook/eda/section3/eda35c.htm

[11]. http://www.itl.nist.gov/div898/handbook/eda/section3/autocopl.htm

[12].http://local.wasp.uwa.edu.au/ pbourke/miscellaneous/correlate/

[13].Allen, G, "Communications Technology Opportunities Using LabVIEW-Controlled RF

Equipment," Proceedings of the ASEE North-Midwest Regional Conference, Educating the 